This item was submitted to Loughborough's Research Repository by the author.

Items in Figshare are protected by copyright, with all rights reserved, unless otherwise indicated.

\title{
A novel phase-aligned analysis on motion patterns of table tennis strokes
}

PLEASE CITE THE PUBLISHED VERSION

http://www.ingentaconnect.com/content/uwic/ujpa/2016/00000016/00000001/art00024

\section{PUBLISHER}

Cardiff Metropolitan University

VERSION

AM (Accepted Manuscript)

\section{PUBLISHER STATEMENT}

This work is made available according to the conditions of the Creative Commons Attribution-NonCommercialNoDerivatives 4.0 International (CC BY-NC-ND 4.0) licence. Full details of this licence are available at: https://creativecommons.org/licenses/by-nc-nd/4.0/

\section{LICENCE}

CC BY-NC-ND 4.0

\section{REPOSITORY RECORD}

Zhang, Zhiqing, Ben J. Halkon, Siaw Meng Chou, and Xingda Qu. 2019. "A Novel Phase-aligned Analysis on Motion Patterns of Table Tennis Strokes". figshare. https://hdl.handle.net/2134/21708. 


\title{
A novel phase-aligned analysis on motion patterns of table tennis strokes
}

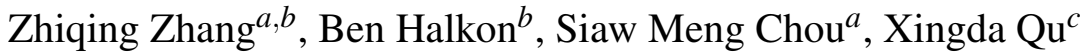

\author{
a. Nanyang Technological University, 50 Nanyang Ave, 639798, Singapore \\ b. Loughborough University, Epinal Way Loughborough, LE113TU, England \\ c. Shenzhen University, Shenzhen Guangdong Province, 518060, China
}

\begin{abstract}
A wide range of human motion represent repetitive patterns particularly in racket sports. Quantitative analysis of the continuous variables during the different phases of the motion cycle helps to investigate more deeply the specific movement of the racket or player. Table tennis biomechanics research to date lacks the necessary detail of phase decomposition and phase-based quantitative analysis. Therefore, this study proposes a novel velocity-based piecewise alignment method to identify the different phases of a table tennis forehand stroke. A controlled experiment was conducted on a number of players of two differing ability levels (experts vs. novices) to implement this novel methodology. Detailed results are shown for the quantitative analysis on multiple strokes of the two groups of participants. Significant differences were found in both the displacement and velocity of the racket movement in the backswing, forward swing and follow-through phases. For example, it is clear that experts strokes show higher racket resultant velocity than novices during both the forward swing and follow-through phases by up to a factor of two. Furthermore, the phase-based approach to analysing racket motions leads to interrogation over a greater duration than the traditional time-based method which is generally only concerned with impact $\pm 0.25 \mathrm{~s}$.
\end{abstract}

keywords: table tennis biomechanics, racket motion, phase alignment.

\section{Introduction}

It is common that human motion in daily activities and particularly in sports involves repetitive patterns. Walking and running are two of the most fundamental of such movements, both of which have received significant attention in the published research. Walking and running are readily accepted as being the combination of several phases, known as the gait cycle. For example, walking included stand phase and swing phase etc (Kirtley, 2006), which were identified by the events like heel-on and toe-off from the ground floor. Racket sports also involve similar cyclical motion patterns, especially in technique training where players practice desired techniques over and over. Such racket sports movements can be biomechanically subdivided into different phases based on racket and ball events in a similar manner to walking and running.

Table tennis is one of the typical racket sports that involves complex movement of the racket and the human arm. Trainees need to repeat certain techniques to return balls fed either by other players or by robots when under multi-ball training. There are different means by which the phases can be distinguished as have been presented by other 
researchers. For example, preparation phase, action phase and recovery phase (Bartlett, 2007); awaiting stage, preparation stage, hitting stage, finishing stage (Mlling and Peters, 2009); preparatory movement, backswing phase, force producing phase, critical instant and follow-through (Alexander and Honish, 2009); preparation phase, main phase, closing phase (Kondri et al., 2006); etc. Despite the fact that different terms for the various names have been defined in different studies, they actually refer to similar components of the racket/arm motion. These phases identify the human motion state by describing the racket movement. In this study, the following names for the table tennis cycle phases will be used: preparatory $(P R)$, backswing $(B S)$, forward swing $(F S)$ and follow-through $(F T)$.

There were known difficulties in the description of different continuous movement cycles since each cycle clearly typically occurs over a different duration, e.g. it may have different length of durations in the forward swing phase of two strokes of the same person. A range of biomechanical studies have focused the analysis of variables on the moment when the ball and racket come into contact (e.g. direction of travel of the racket at contact (Bootsma and Van Wieringen, 1990)) or on the descriptive variables over a duration (e.g. maximum joint torque near contact (Iino and Kojima, 2011)). While these variables represent measurement at a particular instant or of the whole span, motions on other moments were missing in some cases, because the final outcome is the historical accumulation of all previous movement.

Two methods can be applied for the investigation of the continuous movement over a certain time span: either using real time or using "phase time". The former involves the interrogation of a typical event over a fixed time beforehand, for example, Sheppard and Li (2007)'s study was performed on the time span from $300 \mathrm{~ms}$ before contact to $100 \mathrm{~ms}$ after contact. The latter, which is preferred for the research described in this paper, uses common states during a particular phase. Each of the two methods has its advantages and disadvantages. The former enables study of the motion in real time but cannot reliably be applied on instances far away from the aligned event (e.g. racket-ball contact), since results may be affected by fluctuations in the duration of movement cycles from one example event to another. Conversely, the second method can be applied over the full motion cycle since example events are aligned, the compromise being that the actual time information is no longer available. The second method shows more flexibility, but little work in table tennis has employed the approach thus far. In fact, a number of studies have used the first method therefore only investigated a maximum duration of typically $250 \mathrm{~ms}$ before to $100 \mathrm{~ms}$ after contact (Bootsma and Van Wieringen, 1990; Sheppard and Li, 2007; Iino et al., 2008). Rarely have these been extended over the complete cycle follow-up quantitative analyses on the continuous variables over the phases performed as is performed in this article. Others may use the racket displacement or its trajectory for identifying the phase in reviewed studies, e.g. Ramanantsoa and Durey (1994). Although the phase may be comprehensively understandable from the trajectories of racket displacement, there may occur situations that the vertex of the trajectory curve, which is supposed to be used to distinguish the phases, is hard to identify due to a relatively round shape with larger curvature.

This study aims to propose a novel means for identifying the phases of a forehand table tennis stroke, which is based only on the velocity of racket centre motion. An exper- 
imental investigation, including a number of players of two differing ability levels, was conducted as an example implementation of this methodology. In the complementary data analysis, a comparison is applied for the racket motion of table tennis experts and novices under the aligned phases.

\section{Methodology}

\subsection{Experiment}

Two groups of participants were recruited for the experimental investigation. One group contained 10 experts aged $24.1 \pm 1.6$ years, and the other group contained 10 novices aged 23.1 \pm 4.1 years. All of them were healthy male right-handed "shakehand-grip" table tennis players. The experts were professionals recruited from table tennis teams or clubs. The novices were beginners recruited from the general University population without prior formal training from coaches or other professionals.

The experiment was conducted indoors with a standard table tennis table (Figure 1). A ball-feeding machine (Robo-Pong, Newgy, USA) was set up on the opposite side of the table to the participant while an A5 piece of white paper was placed on the same side to serve as a target for the participant to aim at when returning the balls served by the machine. A basic video camera was used to record the landing position of the returned ball on the table during the experiment in order that shots could be included or eliminated from the analysis depending upon whether or not they landed on the target. A standard shakehand-grip racket was provided to the participants with reflective markers placed onto the racket edge (Figure 1) as shown in the figure; the data was captured with an eight-camera motion capture system (Motion Analysis Eagle System, Santa Rosa, USA) with a sampling rate of $100 \mathrm{~Hz}$.

During the experiment, the settings of the ball-feeding machine were controlled so that the balls were propelled from the centre of the table at a speed of around $4 \mathrm{~m} / \mathrm{s}$ toward the participant (Figure 1) every 3 seconds. Participants used a forehand stroke to repeatedly return the balls towards the target while standing on the marked ground lines (no restriction on side standing position) without any initial foot movement. There was an instruction and warming up session during which participants tried to adjust their body movement to hit the ball towards the target as accurately and as quickly as possible. Afterwards, motion capture began and lasted for a total of three minutes.

By reviewing the recording from the video camera, only data of strokes successful returned to the target were included for further analysis. Racket center displacement and velocity were calculated from the data of left and right markers on the racket (Figure 1). The third marker on racket tip was added to calculate racket spatial orientation, which was described as the angles between racket surface and axes planes. Phase alignment was then applied on these variables as is described in detail in the following section.

\subsection{Phase alignment method}

A typical table tennis stroke is made up of four different phases, as presented in Fig. 2, which can be named preparatory $\left(P_{P R}\right)$, backswing $\left(P_{B S}\right)$, forward swing $\left(P_{F S}\right)$ and followthrough $\left(P_{F T}\right)$ phases. The critical septal moments between the phases are marked as $T_{0}$, 


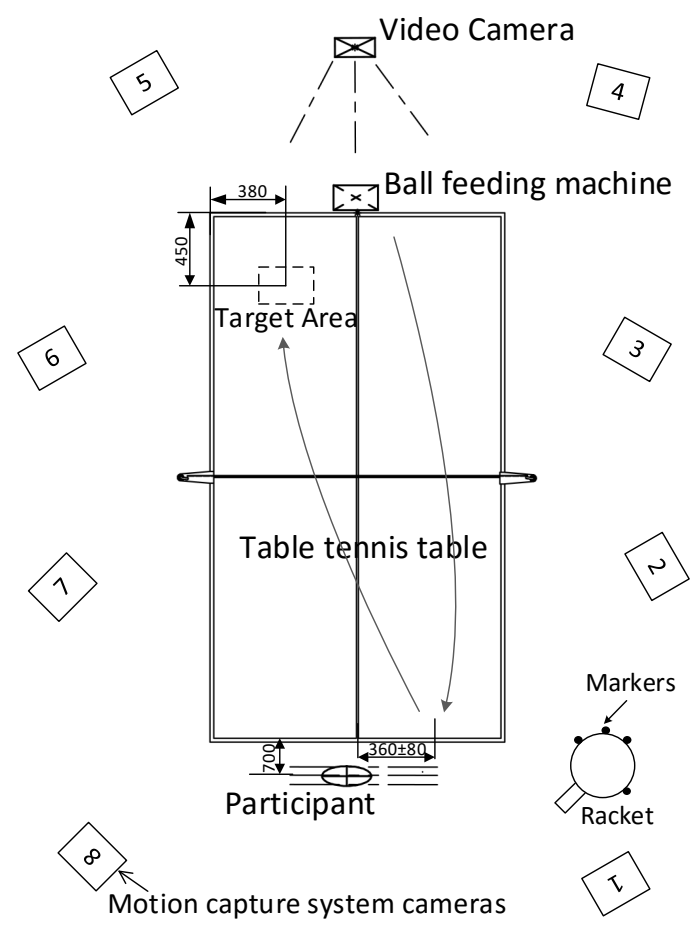

Figure 1: Experiment setup

$T_{2}, T_{3}$ and $T_{4}$ respectively. In practice, the $T \mathrm{~s}$ are first identified from the racket velocity curve, with the $P$ s then readily retrieved. An example racket velocity curve is shown in Fig. 3; it is the resultant speed of forward and leftward velocity (i.e. projected velocity on the ground floor plane) as the motion relative to this plane is of the most interest in this study. With the velocity curves, the $T$ s are determined from the time points with local maximum or minimum velocity. In other words, they $T$ s are generally located where the acceleration is zero.

The prominent $T_{3}$ moment is coincident with or very close to the moment when the racket and ball come into contact; this is supported by previous research (Bootsma and Van Wieringen, 1990; Ramanantsoa and Durey, 1994; Sheppard and Li, 2007). According to the data in this study, however, the $T_{0}$ moment, where the player, and therefore the racket, starts to move from a relatively static pose, was generally challenging to reliably identify. This can be seen by inspection of the typical example data shown in Fig. 3. A common solution to this is to set a speed threshold value at which, whenever the backswing speed exceeds that value (e.g. toe-off event in gait), that point is regarded as the beginning of $P_{0}$. However, such a value is generally somewhat arbitrarily defined and may therefore affect $T_{0}$ in turn to a significant extent. This bias may be especially large when it comes to a racket sport, because the phases are all relatively short in time. In fact, Fig. 3 shows two parts under the backswing phase: $T_{0}-T_{1}$ and $T_{1}-T_{2}$ (Fig. 3), where the $T_{1}$ is defined as the moment with the maximum backswing speed. Since $T_{0}$ is not sufficiently reliably identified from the velocity data, the duration $T_{1}$ to $T_{2}$ was used for the definition of the backswing phase in the remainder of this study.

After the various phases of each of the strokes were identified, all the displacement and 


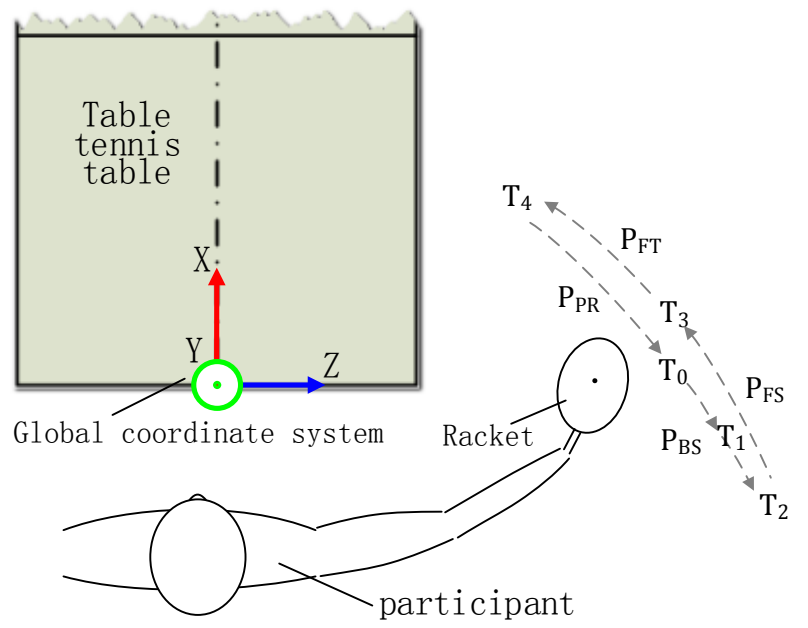

Figure 2: Different phases of a table tennis forehand stroke

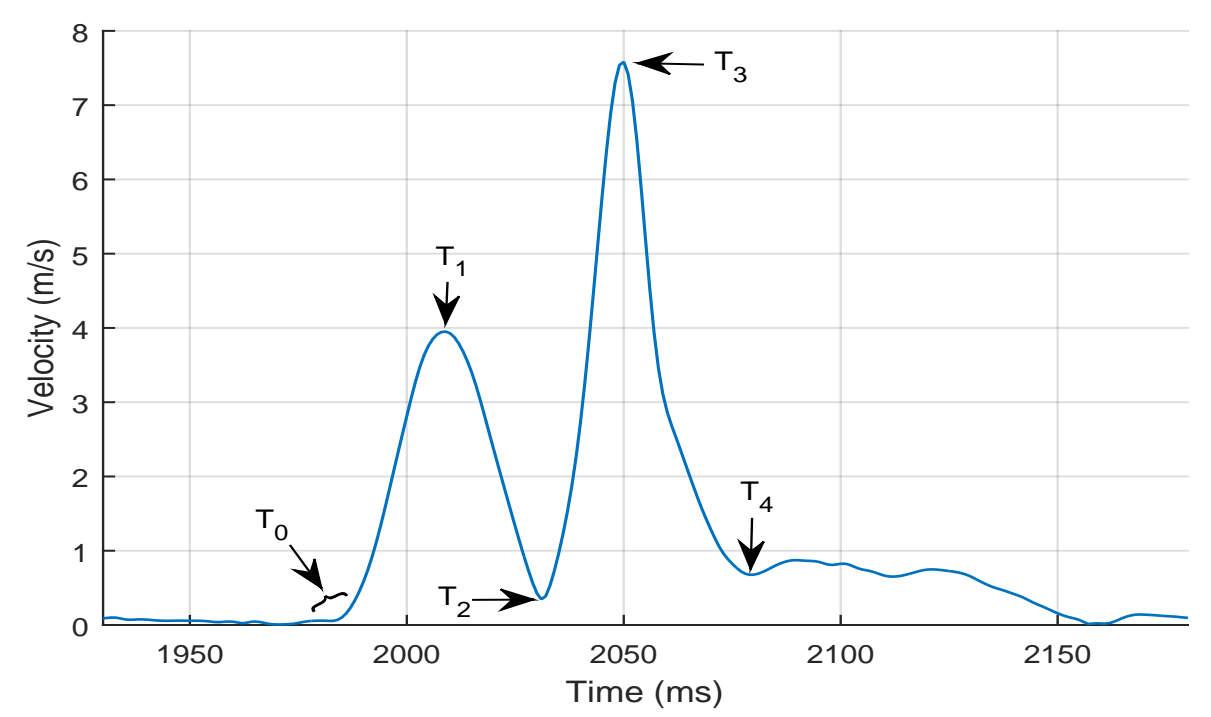

Figure 3: A typical example of racket center resultant velocity profile

velocity variables were aligned using a piecewise linear normalization: each original time series data $T_{\text {before }}$ was converted to $T_{a f t e r}$ based on Eq. $1\left(P_{P R}\right.$ is not of interest and is therefore not presented). The new data were based on aligned phase time $1-4$, where the $T_{1}$ to $T_{4}$ in Fig. 2 were aligned to phase time 1 to 4 respectively. Fig. 4 is included to enable illustration of the phase alignment. Since every stroke is over a different total duration, strokes were all firstly aligned to the moment of racket-ball contact (i.e. to maximum velocity) as shown in Fig. 4a; once phase aligned, the curves were completely aligned over $T_{1}$ to $T_{4}$ as shown in Fig. $4 \mathrm{~b}$.

$$
T_{\text {after }}=\left\{\begin{array}{l}
\frac{T_{\text {before }}-T_{1}}{T_{2}-T_{1}}+1, T_{1} \leq T_{\text {before }}<T_{2} \\
\frac{T_{\text {before }}-T_{2}}{T_{3}-T_{2}}+2, T_{2} \leq T_{\text {before }}<T_{3} \\
\frac{T_{\text {before }}-T_{3}}{T_{4}-T_{3}}+3, T_{3} \leq T_{\text {before }} \leq T_{4}
\end{array}\right.
$$




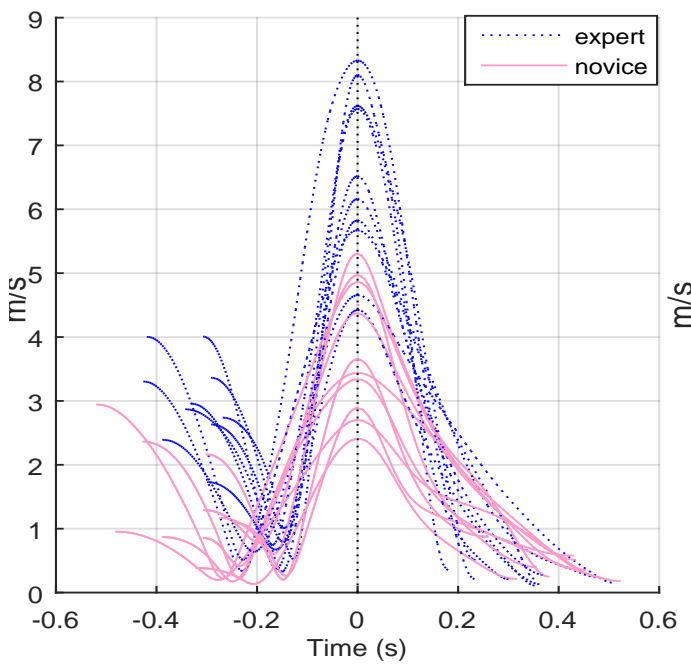

(0: moment with maximum velocity)

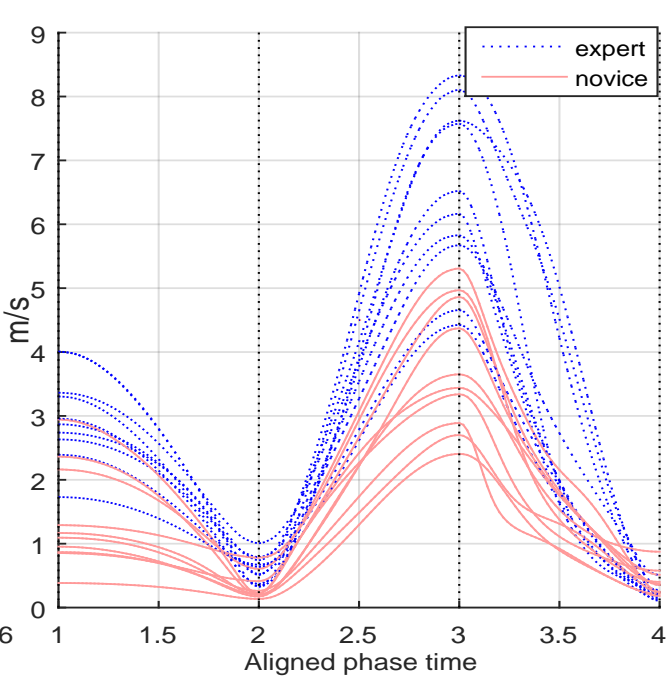

(1-2: BS; 2-3: FS; 3-4: FT)

Figure 4: Racket center velocity before (a) and after (b) alignment

\section{Results}

\subsection{Phases}

The stroke accuracy, which is the ratio of the number of successful strokes to the total number of strokes, and the time of each of the phases $\left(P_{B S}, P_{F S}\right.$ and $\left.P_{F T}\right)$ for each of the participants are shown in Fig. 5. As can be seen, experts have higher stroke accuracy $(83.55 \pm 11.92 \%)$ than novices $(49.95 \pm 12.10 \%)$ according to calculation. In this figure, each participant had a different duration for each of the phases. In addition, the duration of each stroke for each participant varied to a different extent; experts also displayed variability across different strokes, though relatively smaller to those of the novices.

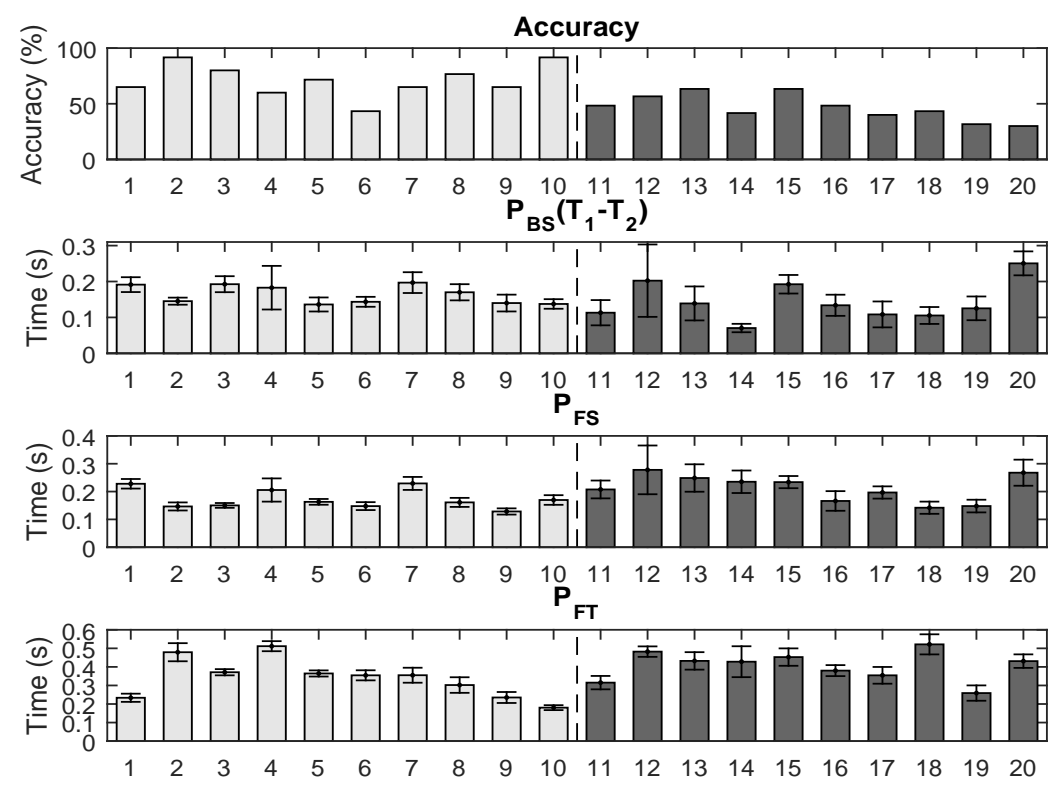

Figure 5: Stroke accuracy and phase durations for all participants (1-10: experts; 11-20: novices) 
A quantitative comparison of these phase time duration and variabilities between the expert group and the novice group was applied as shown in Table 1. It can be observed that experts generally spent more time in the backswing phase, but less time in the forward swing and follow-through phases. However, following a statistical t-test the significance of these differences was found to be somewhat low. The variability, however showed more consistent results in that the expert group displayed less variability in all the three phases than the novices; the forward swing phase and follow-through phase showed significant differences.

Table 1: Comparison of mean and variabilities of durations of each phase between experts and novices

\begin{tabular}{|c|c|c|c|c|}
\hline & & Experts & Novices & p-value \\
\hline \multirow{3}{*}{$\begin{array}{l}3 \\
\stackrel{\mathbb{D}}{J} \\
\stackrel{3}{3}\end{array}$} & $P_{B S}$ & $0.16 \pm 0.03$ & $0.14 \pm 0.05$ & 0.319 \\
\hline & $\mathrm{P}_{\mathrm{FS}}$ & $0.17 \pm 0.04$ & $0.21 \pm 0.05$ & $0.053 * *$ \\
\hline & $\mathrm{P}_{\mathrm{FT}}$ & $0.34 \pm 0.11$ & $0.41 \pm 0.08$ & 0.126 \\
\hline \multirow{3}{*}{ 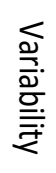 } & $P_{B S}$ & $0.02 \pm 0.01$ & $0.04 \pm 0.02$ & 0.128 \\
\hline & $P_{F S}$ & $0.02 \pm 0.01$ & $0.04 \pm 0.02$ & $0.010 *$ \\
\hline & $\mathrm{P}_{\mathrm{FT}}$ & $0.03 \pm 0.01$ & $0.04 \pm 0.02$ & $0.017^{*}$ \\
\hline
\end{tabular}

Note: $*$ indicates significance $(p<0.05)$; ** indicates marginal significance $(0.05<p<0.1)$.

\subsection{Phase-aligned racket movement}

Table 2 shows the racket motions both at the specific moments 1, 2, 3 and 4, and the phase time in between: $P_{B S}\left(T_{1}-T_{2}\right), P_{F S}\left(T_{2}-T_{3}\right)$ and $P_{F T}\left(T_{3}-T_{4}\right)$. The racket center displacement and velocity include the racket center movement in the $x$-, $y$ - and $z$-directions of the global coordinate system (Fig. 2), which are $R C_{x}, R C_{y}$ and $R C_{z}$ respectively. The racket angular displacement and angular velocity include the angles of the racket front surface plane against the $x-O-y, y-O-z$ and $x-O-z$ planes of the global coordinate system, which are $R \Theta_{X Y}, R \Theta_{Y Z}$ and $R \Theta_{X Z}$ respectively. Statistical $t$-tests were applied on these variables on the phase time at a significance level of 0.05 . The results are marked as " $\mathrm{H}$ " (experts with higher values), "L" (experts with lower values) or "O" (no difference), while a "-" is used to represent the tendency of change inside a phase. Of the various variables included, the racket center velocity $R C_{x}$ is shown in Fig. 6 as an example.

From the table it can be seen that there were few differences in the distance of racket to the table $\left(R C_{x}\right)$ during all of the phases. Similarly there were few differences in the location of the racket when the participant hit the balls ( $R C$ at phase time 3 ) which would of course be expected for a consistent ball feeding machine. However, it can readily be observed that experts generally moved their racket more downward and leftward during backswing, and had a larger range of movement $\left(R C_{z}\right)$ when they ended their stroke. Experts also generally had much faster backswings $\left(R C_{x}\right.$ smaller because of the negative sign) and produced much higher speed in the forward $\left(R C_{x}\right)$ and upward $\left(R C_{y}\right)$ directions at ball-racket contact. There was, however, little difference in the leftward $\left(R C_{z}\right)$ direction at the contact moment. Regarding the spatial direction of their rackets, the experts 
Table 2: Comparison of different variables of racket motion on phase time with $T_{1}, T_{2}, T_{3}$ and $T_{4}$ highlighted

\begin{tabular}{|c|c|c|c|c|c|c|c|c|}
\hline Variables & & 1 & $1-2$ & 2 & $2-3$ & 3 & $3-4$ & 4 \\
\hline \multirow{3}{*}{$\begin{array}{c}\text { Center } \\
\text { displacement }\end{array}$} & $\mathrm{RC}_{\mathrm{x}}$ & 0 & 0 & 0 & 0 & 0 & 0 & 0 \\
\hline & $\mathrm{RC}_{\mathrm{y}}$ & $\mathrm{L}$ & L & $\mathrm{L}$ & L-O & 0 & $\mathrm{O}-\mathrm{H}-\mathrm{O}$ & $\mathrm{O}$ \\
\hline & $\mathrm{RC}_{\mathrm{z}}$ & $\mathrm{L}$ & $\mathrm{L}$ & L & L-O & 0 & O-L & $\mathrm{L}$ \\
\hline \multirow{3}{*}{$\begin{array}{l}\text { Center } \\
\text { velocity }\end{array}$} & $\mathrm{RC}_{\mathrm{x}}$ & $\mathrm{L}$ & $L$ & $L$ & $\mathrm{~L}-\mathrm{O}-\mathrm{H}$ & $\mathrm{H}$ & H-O-L-O & $\mathrm{H}$ \\
\hline & $\mathrm{RC}_{\mathrm{y}}$ & 0 & $\mathrm{O}-\mathrm{H}$ & $\mathrm{H}$ & $\mathrm{H}-\mathrm{O}-\mathrm{H}$ & $\mathrm{H}$ & $\mathrm{H}-\mathrm{O}$ & $\mathrm{O}$ \\
\hline & $\mathrm{RC}_{\mathrm{z}}$ & 0 & 0 & $\mathrm{H}$ & $\mathrm{H}-\mathrm{O}$ & 0 & $\mathrm{~L}-\mathrm{O}$ & $\mathrm{O}$ \\
\hline \multirow{3}{*}{$\begin{array}{c}\text { Angular } \\
\text { displacement }\end{array}$} & $R \Theta_{X Y}$ & 0 & $\mathrm{O}$ & 0 & O-L-O & 0 & $\mathrm{O}-\mathrm{H}-\mathrm{O}$ & 0 \\
\hline & $\mathrm{R} \Theta_{\mathrm{YZ}}$ & 0 & $\mathrm{O}-\mathrm{H}$ & $\mathrm{H}$ & $\mathrm{H}-\mathrm{O}$ & 0 & $\mathrm{O}-\mathrm{H}-\mathrm{O}$ & O \\
\hline & $\mathrm{R} \Theta_{\mathrm{xz}}$ & 0 & $\mathrm{H}$ & $\mathrm{H}$ & $\mathrm{H}$ & $\mathrm{H}$ & $\mathrm{H}-\mathrm{O}$ & $\mathrm{O}$ \\
\hline \multirow{3}{*}{$\begin{array}{l}\text { Angular } \\
\text { velocity }\end{array}$} & $R \Theta_{X Y}$ & 0 & O-L & $\mathrm{L}$ & L-O-H & $\mathrm{H}$ & $\mathrm{H}-\mathrm{O}$ & $\overline{0}$ \\
\hline & $\mathrm{R} \Theta_{\mathrm{Yz}}$ & 0 & $\mathrm{O}$ & $\mathrm{O}$ & O-L-O & 0 & $\mathrm{O}-\mathrm{H}-\mathrm{O}$ & $\mathrm{O}$ \\
\hline & $\mathrm{R} \Theta_{\mathrm{xz}}$ & $\mathrm{O}$ & $\mathrm{O}$ & o & O-L-O & 0 & O-L & $\mathrm{L}$ \\
\hline
\end{tabular}

Note: $R C$ Racket center movements; $R \Theta$ Racket angular motions; $1-4$ phase time $T_{1}-T_{4} ; H, L$ and $O$ results of comparison.

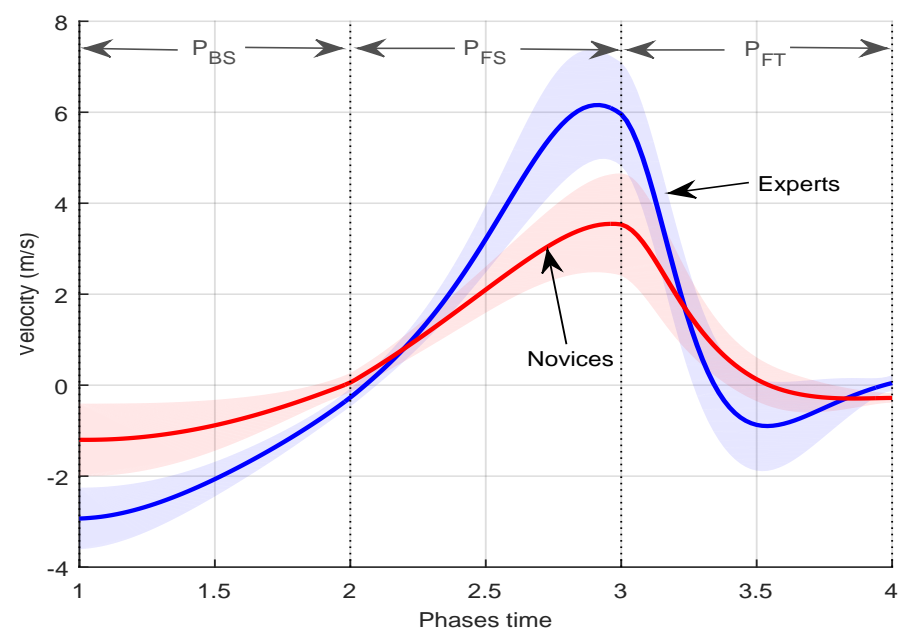

Figure 6: Comparison result of racket center velocity $R C_{x}$

exhibited more downward facing of the racket face $\left(R \Theta_{X Z}\right)$ during the backswing and the forward swing phases. In the angular speed of the racket direction against $x$-O $-y$ plane experts had lower angular speed at the beginning of forward swing but higher at the end, which indicted that expert rotated their racket with more significance (positive angular acceleration).

\section{Discussion and conclusion}

From the results of the experiment described in the previous section, it can be seen that there are different statistical significances regarding different phases of the racket movement. Such a result is significant as it confirms that there is an opportunity to improve novices performance through coaching to move them towards the characteristics of experts. 
Table 2 gives an insight to racket motion over a more extended duration (i.e. during $P_{B S}$, $P_{F S}$ and $P_{F T}$ ) with the method of piecewise phase alignment in place of that used in other other real-time-based studies. In addition, it confirms the situation at the start and at the end of the phase do not necessarily indicate what occurs within the phase itself (e.g. displacement $R C_{y}$ and velocity $R C_{x}$ in phase time $3-4$ ). Fig. 6 shows an example of the racket center velocity $R C_{x}$ in which the variable between the equally spaced in time sampled points can be observed. The velocity $R C_{x}$ has a " $\mathrm{H}$ " at both $T_{3}$ and $T_{4}$ (Table 2), which may give a wrong indication that the experts always had a higher speed than the novices if no information inside the follow-through phase is given. In fact, the tendency "O-L-O" between $T_{3}$ and $T_{4}$ indicates that the velocity of experts decreased more between $T_{3}$ and $T_{3.5}$, as also shown in Fig. 6. Therefore, the experts had more deceleration on the racket after the contact was finished, which may contribute to a faster return to the preparatory position. Therefore, a phase-aligned analysis may be helpful in studying the continuous movement inside a cycle.

The decision to use $T_{1}$ in place of $T_{0}$ for the determination of the backswing phase is justified. Besides the fact that $T_{0}$ is more difficult to reliably determine in semi-automated processing than $T_{1}$, a breakdown of $T_{0}$ to $T_{2}$ by $T_{1}$ may be a more reasonable means for phase decomposition due to the way a human participant controls the racket. As can be seen from Fig. 3, the five moments $T_{0}, T_{1}, T_{2}, T_{3}$ and $T_{4}$ divide the curve in between into 5 monotonically increasing or decreasing parts. In fact, they are also the moments related to significant change of racket acceleration: the player attempts to change the direction he produces force on the racket. $T_{1}$ is the moment a player starts to decelerate his racket which might be just as important as $T_{0}$ that he starts to accelerate his racket.

This method applies a novel way to identify phases using maximum or minimum speed rather than maximum displacement as commonly used by researchers and others. $T_{2}$ under the traditional method, for example, may include the time of extra span of acceleration or deceleration during which the player is already applying force to the racket. The difference between the methods may be as short as $0.02 \mathrm{~s}$ according to estimation on the participants during the current experiment, but it is about $12 \%$ of a phase. A more significant source of error is from the identification of the position of maximum displacement. The racket moves in a three-dimensional trajectory and it is therefore difficult to define the maximum displacement as minimum $y$ or $z$, or even the vertex of curve which may still be hard to identify (e.g. Fig. 7). The slower speed around $T_{2}$ causes more collected data points by a fixed-frequency motion capture system, which leads to magnified time bias.

This is more consistent that all the $T$ s are identified from the same source (i.e. velocity) in the method. It has no dependence on the high speed camera, which is usually used to track the racket and ball to identify the contact moment. Besides, it also shows high potential that a acceleration measurement (e.g. accelerometer, inertial measurement unit) can be applied to track the whole phases of a table tennis stroke. As there are also evidences that players produce maximum racket speed at or quite near the moment of "ball" and racket contact in other racket sports like tennis (Elliott et al., 1995) and badminton (Kwan et al., 2011), this method may also be possible to be implemented to other racket sports studies. 


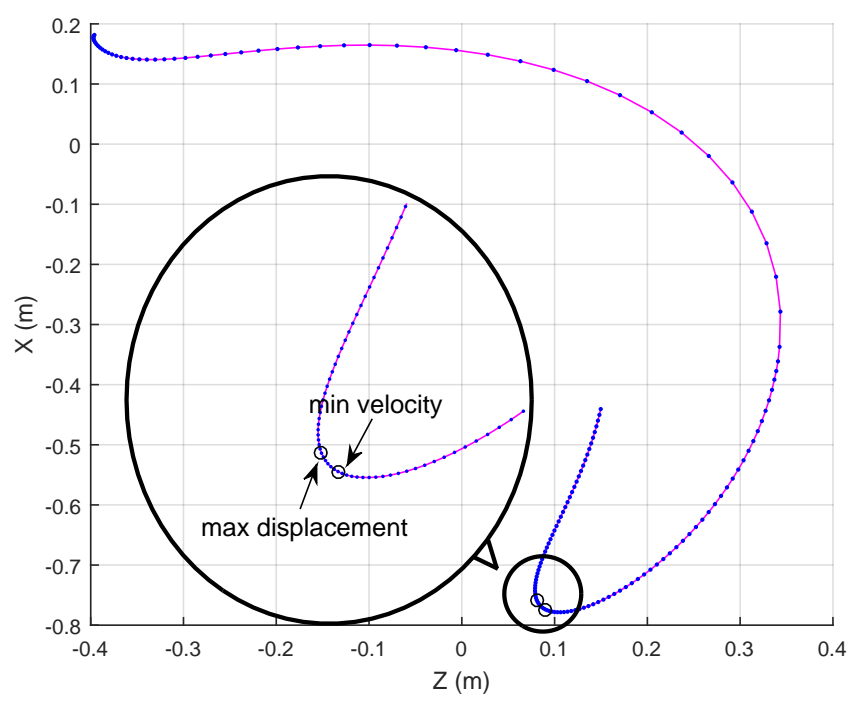

Figure 7: Maximum displacement vs. maximum velocity points identified

\section{References}

Alexander, M. and Honish, A. (2009). Table tennis: A brief overview of biomechanical aspects of the game for coaches and players. Report, Faculty of Kinesiology and Recreation Management, University of Manitoba.

Bartlett, R. (2007). Introduction to sports biomechanics: Analysing human movement patterns. Routledge.

Bootsma, R. and Van Wieringen, P. C. (1990). Timing an attacking forehand drive in table tennis. Journal of Experimental Psychology: Human Perception and Performance, 16(1):21-29.

Elliott, B., Marshall, R. N., and Noffal, G. J. (1995). Contributions of upper limb segment rotations during the power serve in tennis. Journal of Applied Biomechanics, 11:433442.

Iino, Y. and Kojima, T. (2011). Kinetics of the upper limb during table tennis topspin forehands in advanced and intermediate players. Sports Biomechanics, 10(4):361-377.

Iino, Y., Mori, T., and Kojima, T. (2008). Contributions of upper limb rotations to racket velocity in table tennis backhands against topspin and backspin. Journal of Sports Sciences, 26(3):287-293.

Kirtley, C. (2006). Clinical gait analysis: theory and practice. Elsevier Health Sciences.

Kondri, M., Furjan-Mandi, G., and Medved, V. (2006). Myoelectric comparison of table tennis forehand stroke using different ball sizes. Acta Universitatis Palackianae Olomucensis. Gymnica, 36(4).

Kwan, M., Andersen, M. S., Cheng, C.-L., Tang, W.-T., and Rasmussen, J. (2011). Investigation of high-speed badminton racket kinematics by motion capture. Sports Engineering, 13(2):57-63. 
Mlling, K. and Peters, J. (2009). A computational model of human table tennis for robot application, pages 57-64. Springer.

Ramanantsoa, M. and Durey, A. (1994). Towards a stroke construction model. International Journal of Table Tennis Science, 2(2):97-114.

Sheppard, A. and Li, F. X. (2007). Expertise and the control of interception in table tennis. European Journal of Sport Science, 7(4):213-222. 